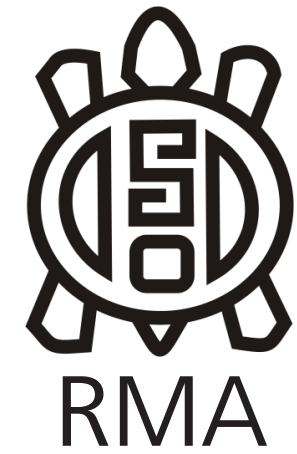

Arqueología

\section{Arqueología e Imágenes. Fuentes iconográficas para el estudio del pasado industrial en el sitio Ingenio Lastenia(Dpto. Cruz Alta, Tucumán, Argentina)}

\author{
Archeology and Images. Iconographic sources for the study of the \\ industrial past at the Ingenio Lastenia Site \\ (Cruz Alta Department, Tucumán, Argentina)
}

Fernando Andrés Villar*, Marina Luciana Aride ${ }^{\star *}$

*CONICET, Instituto Superior de Estudios Sociales, Instituto de Arqueología y Museo, Facultad de Cs. Naturales, Universidad Nacional de Tucumán. E-mail: fer_villar15@hotmail.com

**Facultad de Artes, Universidad Nacional de Tucumán. E-mail: luciana.aride12@gmail.com

\begin{abstract}
Resumen
El sitio Ingenio Lastenia está constituido por los restos de una unidad de producción de derivados de la caña de azúcar que funcionó en la provincia de Tucumán (Argentina) entre 1834 y 1966. Sus más de 130 años de funcionamiento lo convierten en testigo de las diversas etapas atravesadas por la industria azucarera desde sus orígenes. Ante esta condición, su estudio desde la Arqueología Histórica-y desde la Arqueología Industrial como parte de esta-constituye un aporte de gran relevancia para la comprensión del pasado azucarero argentino. Considerando a las imágenes históricas como un elemento de gran valor documental para el estudio del pasado, desde los inicios de nuestras investigaciones -en 2013- hasta la actualidad hemos recopilado numerosas imágenes de la fábrica que abarcan un rango temporal entre 1880 a 1966. Los análisis realizados sobre una serie de fuentes iconográficas -grabados y fotografías- históricas correspondientes a los años 1892, 1904, 1907, 1922 y 1928, generaron resultados que permitieron: a) Ubicar en el campo los espacios representados. b) Obtener una percepción del paisaje fabril de fines de siglo XIX y principios de siglo XX. c) Aproximarnos al contexto de producción de las imágenes. d) Indagar en los sistemas tecnológicos utilizados en la fábrica. e) Definir una secuencia cronológica relativa para las modificaciones ocurridas sobre una serie de estructuras arquitectónicas dentro de un lapso de 30 años (1892-1922).
\end{abstract}

Palabras clave: Arqueología; Arqueología Industrial; Fuentes iconográficas; Industria Azucarera; Argentina.

\begin{abstract}
The Ingenio Lastenia site is made up of the remains of a sugar cane derivatives production unit that operated in the province of Tucumán (Argentina) between 1834 and 1966. Its more than 130 years of operation make it a witness to the various Stages crossed by the sugar industry from its origins. Faced with this condition, its study from Historical Archeology -and from Industrial Archeology as part of it-constitutes a contribution of great relevance to the understanding of the Argentine sugar past. Considering historical images as an element of great documentary value for the study of the past from the beginning of our investigations -in 2013- to the present day we have compiled numerous images of the factory that cover a time range between 1880 to 1966. The analyses carried out on a series of historical iconographic sources -engravings and photographs-corresponding to the years 1892, 1904, 1907, 1922 and 1928, they generated results that allowed: a) Locating the spaces represented in the field. B) Obtain a perception of the manufacturing landscape of the late nineteenth and early twentieth centuries. C) Approach the context of production of the images. D) Investigate the technological systems used in the factory. E) Define a relative chronological sequence for the modifications that have occurred on a series of architectural structures within a span of 30 years (1892-1922).
\end{abstract}

Keywords: Archaeology; Industrial Archaeology; Iconographic Sources; Sugar Industry; Argentina.

El presente trabajo se encuadra en el proyecto de tesis doctoral del primer autor, titulado: Producción, cotidianeidad y disciplinamiento social en un Ingenio Azucarero durante el siglo XIX. Una aproximación al
Sitio Ingenio Lastenia (Dpto. Cruz Alta, Tucumán) desde la Arqueología Industrial. Esta investigación, enmarcada dentro de las propuestas de la Arqueología Industrial (Palmer y Neaverson 1998; Symonds 2005), tiene por 
objetivo abordar desde una perspectiva arqueológica, el proceso de modernización que atravesó el ex Ingenio Lastenia (1834 - 1966) a lo largo de su historia y las implicancias sociales que acompañaron a dicho proceso.

En este trabajo en particular destacamos una serie de análisis de fuentes documentales iconográficas -pinturas, grabados, fotografías, etc.- que poseen una relevancia fundamental y deben ser debidamente analizadas como fase previa a las intervenciones arqueológicas sobre el sitio. Pues en ocasiones, como en el presente caso, este tipo de análisis son esenciales para proyectar de manera eficiente trabajos de campo, interactuar con la información procedente de los mismos e interpretar y comprender procesos acontecidos en el pasado.

En las páginas siguientes, exponemos los análisis realizados sobre una serie de fuentes iconográficas correspondientes a los años 1892, 1904, 1907, 1922 y 1928, en las que está representado el canchón del ex Ingenio Lastenia, sector de la fábrica donde era descargada la caña procedente de los cañaverales, para comenzar el proceso que resultaba en diversos derivados como el azúcar y el alcohol. Las fuentes mencionadas otorgan una perspectiva clara del canchón, de las estructuras arquitectónicas que lo circundan y de otras que, si bien no lo circundan -tal es el caso de las chimeneas-, pudieron ser analizadas aportando elementos de gran relevancia para el estudio arqueológico de la planta.

Haciendo uso de metodologías procedentes de la Arqueología Histórica y la Historia del Arte, los estudios realizados nos permitieron ubicar en el campo entornos y estructuras representadas en las imágenes históricas, indagar en los contextos de producción de las fuentes analizadas, percibir las trasformaciones del paisaje fabril entre 1892 y 1922, y definir una secuencia cronológica relativa para una serie de modificaciones edilicias ocurridas durante el lapso mencionado.

\section{Caso de estudio}

El sitio arqueológico Ingenio Lastenia (en adelante SIL) está ubicado8 $\mathrm{Km}$ hacia el sudeste del casco histórico de la ciudad de San Miguel de Tucumán (6509' 08' longitud Oeste y $26^{\circ} 51^{\prime} 50^{\prime \prime}$ latitud Sur), en la ciudad de Banda del Río Salí, departamento Cruz Alta, provincia de Tucumán, República Argentina (Figura 1). Su emplazamiento se corresponde con un predio de 10 has. delimitadas por muros y compuesto por más de medio centenar de estructuras arquitectónicas - gran parte de ellas en ruinasque conformaron áreas productivas, administrativas y habitacionales durante sus años de funcionamiento.

Durante el siglo XIX la provincia de Tucumán albergó a más de un centenar de fábricas de azúcar y otros derivados de la caña tales como aguardiente y alcohol (Campi 2017), de todas estas unidades productivas, en 1904 solo quedaban
27 portadoras de la más alta tecnología de la época, estando el ingenio Lastenia entre las cinco más productivas (Bialet Masse 1904). A lo largo de su historia, que comienza en la década de 1830 (Villar 2016), el establecimiento cambió sucesivas veces de propietarios y fue objeto de gran cantidad de modificaciones de diversa índole, principalmente relacionadas con cambios productivos y tecnológicos que caracterizaron a las diferentes etapas de la industria azucarera en la provincia (Campi 2017). En el año 1966 cerró sus puertas por orden del gobierno de facto encabezado por el Gral. Onganía, tras anunciarse por decreto-ley 16.926, "La intervención amplia y total de los ingenios azucareros denominados Bella Vista, Esperanza, La Florida, Lastenia, La Trinidad, Nueva Baviera y Santa Ana, todos ellos situados dentro de los límites de la provincia de Tucumán" (República Argentina 1966); y fue uno de los 11 ingenios que dejaron de funcionar entre 1966 y 1968, sumergiendo a la provincia en una profunda crisis económica y social (Nassif 2015).

Considerando los 132 años que el Ingenio Lastenia funcionó como unidad de procesamiento de caña de azúcar (1834 - 1966), podemos afirmar que es un verdadero "testigo" de gran parte de la historia de la industria azucarera argentina. De esta manera su abordaje arqueológico nos permitirá analizar procesos de diversa índole -sistemas productivos, tecnológicos y arquitectónicos, relaciones sociales, vida cotidiana y hábitos de consumo, entre otros- asociados a esta industria en diferentes épocas.

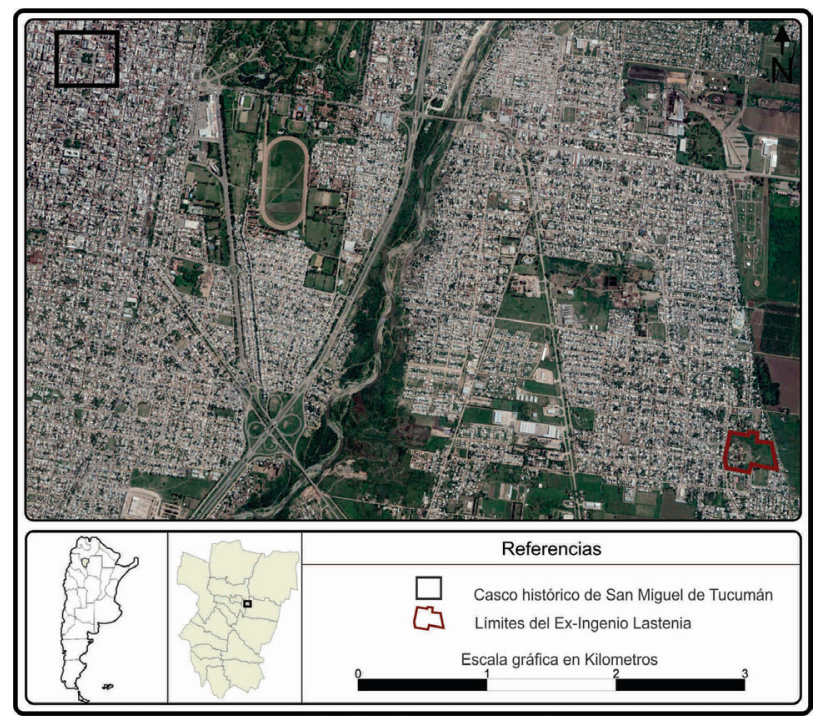

Figura 1. Ubicación del Sitio Ingenio Lastenia (SIL) en relación al casco histórico de San Miguel de Tucumán. Elaboración propia sobre Imagen Satelital extraída de Google Earth Pro. Datos de la Imagen: ( 2019 Google, Image @ 2019 Maxar Technologies.

Figure 1. Location of the Ingenio Lastenia Site (SIL) in relation to the historic center of San Miguel de Tucumán. Own elaboration on Satelital Image extracted from Google Earth Pro. Image Data: (c) 2019 Google, Image (c) 2019 Maxar Technologies. 


\section{Fuentes iconográficas, una ventana hacia el pasado industrial}

Los registros gráficos acompañan a la Arqueología desde su formalización como disciplina a mediados del siglo XIX (Sobrino Simal 1999; Shanks y Svabo 2013), por entonces su función estaba vinculada a dos propósitos básicos; en primer lugar, registrar y documentar ruinas, estructuras y artefactos recuperados en la excavación; en segundo lugar, realizar tomas fotográficas informales de recuerdo personal de los viajes y excavaciones (Ruiz Zapatero 2014), si bien estas funciones siguen existiendo, hoy en día el abanico de posibilidades ofrecidas por las imágenes para la investigación del pasado se ha ampliado de forma sustancial. Desde hace décadas, las fuentes iconográficas (fotografías, pinturas, grabados, litografías y otros medios de expresión plástica) dejaron de ser un objeto de estudio exclusivo de las Artes Visuales y son consideradas un recurso de gran relevancia por parte de diversas disciplinas, entre las que se cuenta la Arqueología (Prince 1988; Sobrino Simal 1999; McGuire y Reckner 2005; Orser 2017).

Dentro del ámbito de la arqueología industrial estas fuentes de información son consideradas un elemento crucial, cuya relevancia radica en el potencial que poseen a la hora de determinar aspectos tales como procesos de producción, distribución y características de edificios y maquinarias, rasgos inherentes a la cotidianeidad en la fábrica y a los sujetos vinculados a ella (Palmer y Neaverson 1998; Sobrino Simal 1999; Orser 2017). Siguiendo a Palmer y Neaverson (1998) podemos considerar que, en cierta manera, estas fuentes dan vida a los paisajes del pasado industrial de una manera muy peculiar, pues en algunos casos tienen una relación directa y privilegiada con las evidencias arqueológicas estudiadas, brindando la posibilidad de acercarnos a la dinámica del contexto estudiado en el momento representado por la imagen.

Desde el siglo XIX la iconografía industrial experimentó un auge extraordinario, pues las representaciones iconográficas acompañaron el avance de la revolución industrial a lo largo y a lo ancho del planeta, publicitando y evidenciando el "progreso" que -según los sectores dominantes de la época- las maquinarias de última generación, el acero y el vapor representaban para las sociedades que las incorporaban (Sobrino Simal 1999). En este marco, grabados y fotografías fueron dos de las técnicas más utilizadas en numerosas publicaciones ilustradas de fines del siglo XIX y principios del XX que prestaron una especial atención en el proceso de industrialización que experimentó por entonces la provincia de Tucumán. Estas manifestaciones, hoy constituyen un tipo de fuente de información fundamental para los estudios arqueológicos del pasado industrial.

Hasta aquí hemos expuesto el valor que las fuentes iconográficas poseen para el estudio del pasado, es decir como documentación histórica. Es necesario aclarar entonces, que al igual que cualquier documento escrito, las fuentes que aquí abordamos son construcciones intencionales, y por ende portadoras del sesgo de quien está detrás de la cámara, el pincel o el lápiz (Orser 2017; González Reyero 2001). Con respecto a esto, Latour (1986) plantea que, dado que las imágenes poseen una apariencia de objetividad y naturalidad, tienden a ser aceptadas como una fuente más fiable que el lenguaje oral o escrito, razón por la cual es necesario poner especial cuidado a la hora de utilizarlas como fuente de información arqueológica o histórica. Por ello, es necesario tener en cuenta que las fuentes iconográficas deben estar sujetas a un análisis crítico antes de ser utilizadas como una fuente de información científica (Palmer y Naeverson 1998).

El aspecto referido en el párrafo anterior fue abordado y sorteado desde hace décadas por la Historia del Arte, desarrollándose desde esta disciplina, metodologías específicas que abordan el estudio de las obras visuales tanto desde su aspecto formal como desde su significado; se indaga así, tanto en la forma como en el contenido de las mismas. Para poder alcanzar este nivel de análisis, Panofsky (2001) sostiene que las obras no deben ser observadas solo como un elemento estético, sino además como un hecho histórico, estando su significado -o contenido- vinculado de manera directa con los hábitos sociales y culturales de su contexto de producción -contemplando al autor como parte de este-, pues toda obra revela, según Panofsky, un sistema de valores e ideas de una época determinada; por esta razón y para alcanzar una correcta interpretación de la misma, el abordaje de una obra debe ser complementado con fuentes bibliográficas contemporáneas a su fecha de creación (Panofsky 2001). En este punto el análisis trasciende el límite de la disciplina artística para incorporarse de lleno en el ámbito de las humanidades en general como una fuente de información cuyo análisis representa un aporte de gran relevancia para el estudio del pasado.

\section{Imágenes y métodos}

Considerando el valor documental que las fuentes iconográficas representan para los estudios desarrollados desde la Arqueología Industrial, una de las primeras tareas llevadas a cabo como parte de los trabajos de gabinete previos a las intervenciones en el campo, fue el relevamiento de fuentes iconográficas en la que estuviese representado el Ingenio Lastenia durante sus años de funcionamiento. Este trabajo consistió en la revisión de fuentes documentales primarias y secundarias (Sensu Orser 2017), dentro de las cuales se destacan, en primer lugar, diversas publicaciones editas como libros, periódicos, revistas y álbumes; en segundo lugar, imágenes procedentes del acervo de fotografías del departamento de Documentos Fotográficos del Archivo General de la Nación (AGN), de las colecciones digitalizadas por el Laboratorio de Digitalización del Instituto Superior de Estudio Sociales (LADI - ISES - CONICET) y de 
los archivos del diario La Gaceta.

En segunda instancia, adaptamos a los recursos tecnológicos actuales una metodología de larga data, la superposición de fotografías históricas en la escena actual, propuesta por Prince (1988) y utilizada por McGuire y Reckner (2005) en sus trabajos sobre la represión de trabajadores mineros en el sur de Colorado a principios del siglo XX. Así, haciendo uso de imágenes satelitales de alta resolución y de reconstrucciones tridimensionales del área de estudio que, en base a estas imágenes, brinda el software Google Earth Pro, obtuvimos perspectivas actuales homólogas a las fotografías aéreas históricas relevadas durante el proceso de recopilación documental. Este método nos permitió ubicar en el campo los espacios representados, interpretar la distribución espacial de las edificaciones e identificar estructurasen ruinas o desaparecidas.

En lo que respecta al análisis intrínseco de las imágenes, nos apoyamos en el método de análisis IconográficoIconológico, desarrollada por Erwin Panofsky para el estudio y análisis de obras de arte, una metodología que, si bien fue pensada para la pintura, también es aplicable a la fotografía (Barboza Martínez 2006; Agustín Lacruz 2010), sus bases han sido utilizadas en investigaciones desarrolladas desde diversas ramas de las humanidades y las ciencias sociales -incluyendo a la Arqueología(Domeneghini 2019; Kligmann y Falchi 2018; Januarius y Teughels 2009; Moreno Pulido 2007; Barboza Martínez 2006) y deja abierta la posibilidad de que el investigador realice sus propias contribuciones o modificaciones sobre el método (Panofsky 2001).

Esta propuesta metodológica establece tres niveles de análisis:

1) Nivel primario o pre-iconográfico, es el nivel más básico de comprensión y consiste en la identificación física de los elementos que componen la obra -seres humanos, animales, edificios, herramientas, etc.- (Panofsky 2001).

2) Nivel secundario o iconográfico, en este nivel de análisis se condensan los elementos identificados en el nivel primario para lograr una primera interpretación global de la representación. Para ello, se presupone una familiaridad con los temas o conceptos específicos representados en la imagen. Para poder llevar adelante este proceso el investigador debe haber adquirido determinados conocimientos, a través de la lectura o por tradición oral (Panofsky 2001), que le permitan comprender, por ejemplo, que una imagen de un espacio abierto en el que confluyen determinados elementos -personas, vías, grúas, atados de caña, carros y vagones cargados con cañas, conductora de caña, grandes edificios y chimeneasse trata de un contexto industrial, y más específicamente del canchón de un ingenio azucarero.

3) Nivel terciario o iconológico, en este nivel se profundiza sobre el contenido de la imagen y puede llevarse adelante en complementación de otras fuentes. Aquí el investigador debe indagar sobre el mensaje ideológico, la expresión de época que representa, el contexto social y cultural de producción; todos ellos elementos que están íntimamente ligados a la finalidad de la obra, un aspecto que debe ser considerado desde el inicio del análisis. De esta manera, el nivel iconológico del estudio, posibilita una aproximación a la actitud básica de una nación, un período, una clase, una creencia religiosa o filosófica (Panofsky 2001).

\section{Resultados}

De la actividad de recopilación de fuentes iconográficas resultaron un total de 27 imágenes, que incluyen fotografías y grabados con representaciones de la fábrica y abarcan un rango temporal que va de 1880 hasta 1966. En cinco de estas 27 imágenes identificamos un mismo sector de la fábrica representado en diferentes años. Se trata de un grabado y cuatro fotografías que nos otorgan vistas del canchón del ingenio Lastenia durante los años 1892, 1904, 1907, 1922 y 1928.

La imagen correspondiente a 1928 es una fotografía aérea tomada en sentido este-oeste, que presenta una perspectiva general del ingenio en la cual es claramente perceptible el canchón de la fábrica. Tras aplicar la técnica de superposición de imágenes combinando esta fotografía y una perspectiva tomada de un modelo tridimensional disponible en el Software Google Earth Pro, logramos establecer la ubicación exacta del canchón de la fábrica y registramos numerosas estructuras hoy desaparecidas (Figura 2).

En lo que respecta a las imágenes de 1892, 1904, 1907 y 1922 -todas representaciones del área demarcada en la Figura 2-, aplicamos la metodología propuesta por Panofsky (2001) a cada una de ellas, poniendo especial énfasis en la caracterización de los elementos arquitectónicos presentes en las imágenes y definiendo una nomenclatura -en letras- para cada uno de las edificaciones representadas. A fin de simplificar esta tarea, junto a cada uno de los documentos iconográficos presentamos un esquema de referencia con el contorno de la fachada de cada edificio analizado.

La primera representación analizada (Figura 3), data del año 1892 y es la más antigua con la que contamos hasta el momento para el sector abordado. Se trata de un grabado expuesto en la Estadística Gráfica - Progreso de la República Argentina en la Exposición de Chicago.

El análisis primario de la fuente nos permitió definir un espacio al aire libre rodeado de edificaciones, en el que pueden apreciarse un grupo de personas y otros elementos a los que haremos referencia a continuación.

Los primeros elementos a los que vamos a referir son un muro, cuatro edificios de una planta y una chimenea. Llamamos 


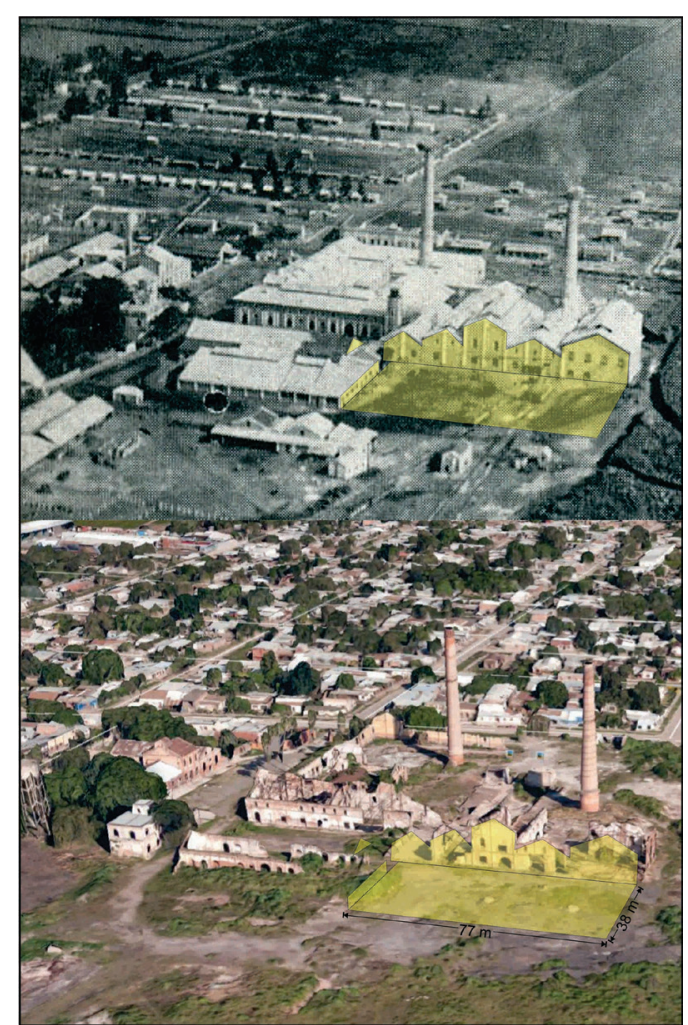

Figura 2. Vista general del Sitio Ingenio Lastenia (SIL) en 1928 y 2016. En amarillo: área correspondiente al canchón del Ingenio. Arriba: Fotografía aérea de la fábrica (Guía de Tucumán 1928). Abajo: imagen tomada de Google Earth Pro; Datos de la imagen: US Dept of State Geographer, (c) 2020 Google, Image @ Maxar Technologies, Image Landsat / Copernicus.

Figure 2. General view of the Ingenio Lastenia Site (SIL) in 1928 and 2016. In yellow: area corresponding to the Sugar Mill yard. Above: Aerial photograph of the factory (Guia de Tucumán 1928). Bottom: image taken from Google Earth Pro; Image data: US Dept of State Geographer, (C) 2020 Google, Image (c) Maxar Technologies, Image Landsat / Copernicus.

a las estructuras, de izquierda a derecha, A, B, C, D, E y F.

A -Muro con barda de tejas en su parte superior.

B - Fachada norte del edificio continuo a "A", posee cubierta de tejas a dos aguas, dos vanos circulares en su parte superior, tres pilastras y dos arcos. A nivel decorativo, se destacan dos molduras que atraviesan la fachada en sentido horizontal.

C - Fachada este del edificio ubicado hacia atrás en la escena, se observa su pared lateral con pilastras y tres arcos que definen aberturas, posee una cubierta de tejas, hacia atrás de la cual se observa una pequeña estructura.

D - Fachada este del edificio central del grabado, presenta en su parte superior dos vanos circulares y molduras similares a las de "B", una pilastra central que va desde la base del edificio hasta la altura de la cumbrera del techo y
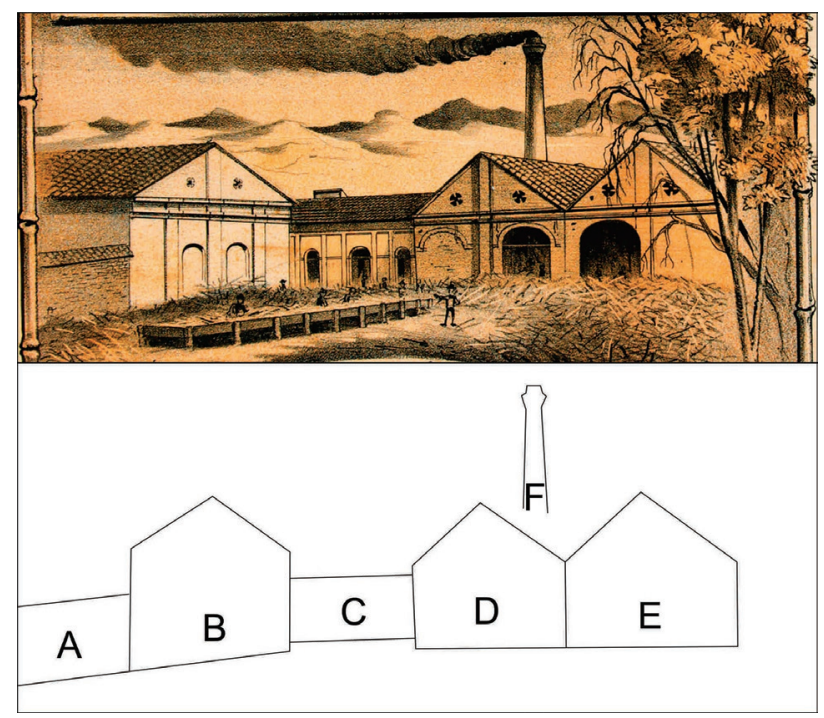

Figura 3. Arriba: Grabado con representación del canchón del Ingenio Lastenia (República Argentina 1982). Abajo: Contorno de la fachada de las edificaciones presentes en la imagen.

Figure 3. Above: Engraving with representation of the Lastenia Sugar Mill yard (República Argentina 1982). Bottom: Facade outline of the buildings present in the image.

dos arcos, uno de los cuales -el derecho- define el acceso al edificio. Su cubierta es de tejas y a dos aguas.

E - Fachada de edificio adosado a "D", con sus mismas características, se diferencia de éste por poseer su acceso sobre la izquierda.

F - Hacia el fondo de la escena se observa una gran chimenea expulsando humo.

En cuanto a las herramientas y a las personas representadas, se destaca la presencia de una estructura cuadrangular con once patas y un grupo de ocho personas en torno de ella. A su vez esta escena está rodeada por una serie de trazos lineales que parecen representar cañas de azúcar dispersas.

A partir del análisis secundario, o iconográfico, inferimos que el grabado de 1892 representa a un grupo de personas trabajando en el canchón del Ingenio Lastenia. La figura permite además indagar en una posible división del trabajo, pues el personaje que está parado solo en el centro de la escena -detalle no menor- con un brazo levantado, pareciera estar guiando la labor de los demás personajes, claramente abocados al trabajo directo con la caña. Por otro lado, la época de la obra y las dimensiones de las edificaciones, fundamentalmente de la chimenea, son una evidencia contundente de la utilización del vapor como principal fuente de energía para el funcionamiento de la unidad de producción.

El análisis iconológico -análisis terciario o de contenido-, implica combinar el estudio de la obra analizada con 
otras fuentes vinculadas a ella (Panofsky 2001). Aquí, debemos considerar que la imagen expuesta en la Figura 3, forma parte de una lámina de $30,70 \times 57,70 \mathrm{~cm}$, en la que se exponen una serie de otros grabados -también de la fábrica-, el nombre de la unidad de producción, de los propietarios y de la provincia (Figura 4).

Esta lámina fue presentada en una publicación destinada a la Exposición Universal de Chicago de 1893 para promocionar la industria nacional, la misma se complementa con una descripción de la fábrica en la que se expone textualmente, "Por el grabado que publicamos en otro lugar el lector podrá formarse una idea de la gran importancia del ingenio azucarero que acabamos de describir" (República Argentina 1892: 33) una declaración textual de la finalidad de la obra.

En función de los elementos mencionados, sostenemos que el propósito de la obra de 1892 fue meramente publicitario. Por un lado, busca transmitir al mundo un aura de grandiosidad para la fábrica y la industria tucumana en general; mientras que por el otro representa una serie de valores que ligan a la industria con el progreso y la civilización, una lógica socio-cultural propia de la Revolución Industrial, es decir del contexto de producción de la obra.

La segunda fuente analizada (Figura 5), fue publicada en 1904 en el informe sobre el estado de la clase obrera, escrito por Juan Bialet Massé. Esta fotografía fue tomada en sentido este-oeste, presentando una perspectiva general de la fábrica en la que se aprecia con claridad el canchón del ingenio.

Desde el punto de vista arquitectónico, en la fotografía se distinguen algunas de las edificaciones representadas en la imagen de 1892, así como también algunas modificaciones e incluso la desaparición de estructuras. Para llevar adelante la descripción de los edificios, continuamos utilizando la nomenclatura definida para 1892, asignando nuevas denominaciones a los edificios ausentes en la Figura 4 y presentes en la Figura 5.

$\mathrm{G}$ - Edificio con techo a dos aguas ubicado en el mismo lugar en que registramos a la estructura "A" para1892, sobre el techo se logra distinguir una posible chimenea. La estructura posee siete aberturas sobre su fachada este y un pequeño vano circular sobre el sector central superior de la fachada norte. Todo el edificio está rodeado por estructuras de madera, aparentemente soportes y andamios para construcción.

B - Fachada norte de edificio, apreciable en el grabado de 1892. Presenta techo a dos aguas, en la fotografía identificamos dos vanos circulares en su parte superior y dos arcos que definen, cada uno, una abertura no apreciable para en 1892.

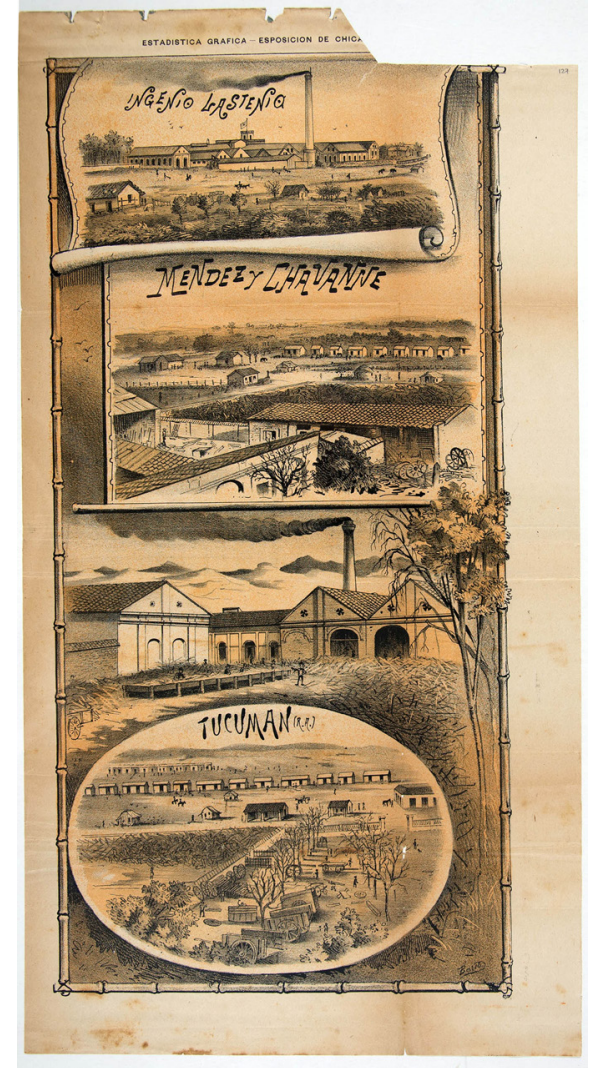

Figura 4. Lamina representativa del Ingenio Lastenia publicada en la Estadística Grafica - Progreso de la República Argentina en la Exposición de Chicago (República Argentina 1892).

Figure 4. Representative sheet of the Lastenia Sugar Mill published in the Estadística Grafica - Progreso de la República Argentina en la Exposición de Chicago (República Argentina 1892).

C - Fachada este del edificio ubicado hacia atrás en la escena, la estructura ya es apreciable en la imagen de 1892, aunque en esta ocasión presenta una diferencia sustancial, posee un segundo nivel inexistente en el grabado expuesto anteriormente; se distinguen siete aberturas, cuatro en planta baja y tres en la primera planta.

D - Edificio observable en 1892, presenta cubierta a dos aguas, vanos circulares en su parte superior y acceso definido por un arco sobre la derecha de la fachada. En su parte posterior se distingue una base cuadrangular con un tanque de agua sobre ella.

E - Edificio adosado a " $D$ " con techo a dos aguas, en su fachada presenta dos vanos circulares en su parte superior $y$ un acceso -definido por un arco- ubicado sobre la izquierda. La edificación es apreciable en la obra de 1892, pero a diferencia de aquella, presenta una abertura cuadrangular (puerta o ventana) sobre la derecha de la estructura.

F-Chimenea sur, perceptible hacia el fondo de la escena, casi al centro de la fotografía. La estructura también es apreciable en 1892. 


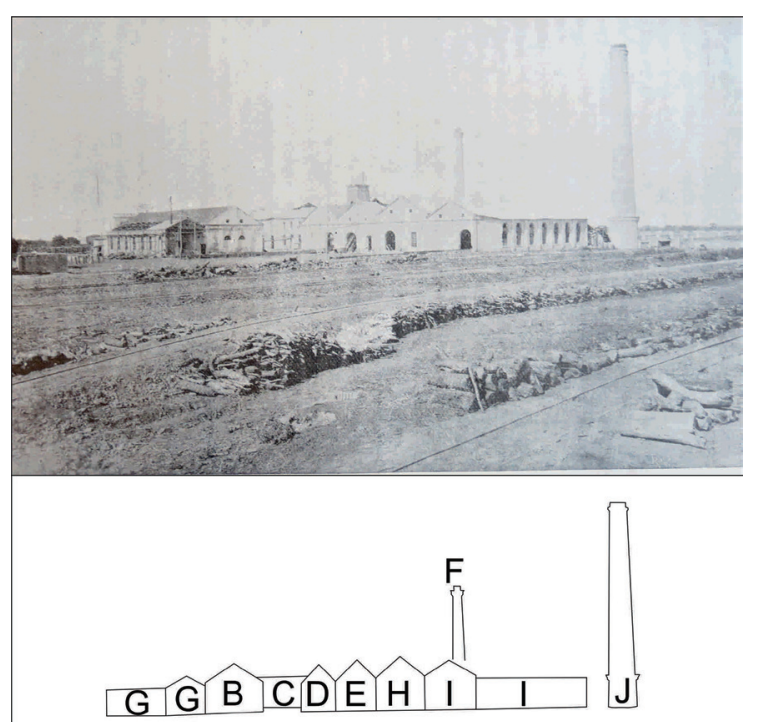

Figura 5. Arriba: Vista general del Ingenio Lastenia publicada en el Informe sobre el estado de la clase obrera (Bialet Massé 1904). Abajo: Contorno de la fachada de las edificaciones presentes en la imagen.

Figure 5. Above: General view of the Lastenia Sugar Mill published in the Informe sobre el estado de la clase obrera (Bialet Massé 1904). Bottom: Facade outline of the buildings present in the image.

$\mathrm{H}$ - Edificio adosado a "E", presenta sus mismas características. No es apreciable en la fuente de 1892.

I- Edificio adosado a "H", apenas más bajo que este, su fachada este presenta las mismas características que " $D$ ". Sobre su pared lateral -fachada norte- se distinguen siete ventanales definidos, cada uno de ellos, por un arco de medio punto.

J - Chimenea norte, ubicada detrás de "I", hacia la derecha en la imagen, no perceptible en el grabado de 1892.

En lo que respecta a los elementos no arquitectónicos, destacamos la presencia de al menos cuatro vías ferroviarias y una gran cantidad de leña depositada sobre los bordes de estas.

Desde el análisis iconográfico -nivel secundario-, destacamos la ausencia de caña y de personas, situación que sugiere que la fotografía fue tomada fuera de la época de zafra, pues de haber sido tomada durante esta época -de fines de mayo a principio de septiembre-, la escena debería haber estado poblada de trabajadores, cañas y posiblemente vehículos para el traslado de estas. Con respecto a las vías y la leña, inferimos que para entonces el ingenio contaba con una importante infraestructura ferroviaria, y que el abastecimiento de leña para combustible llegaba a la fábrica por esta vía.

Para interpretar esta fuente desde un punto de vista iconológico, tomamos en cuenta la finalidad del texto que la acompaña, es decir el informe realizado por Bialet
Massé. El objetivo de dicho documento fue indagar acerca de las condiciones de trabajo y de vida de los obreros del interior del país, siendo Lastenia una de las fábricas visitadas para alcanzar dicho fin. La pésima impresión que se llevó Bialet Massé tras esta visita queda explicita en el informe, el autor se refiere al Ingenio como "bochinche de máquinas y edificios", resalta la mala distribución de sus espacios y maquinarias, el aspecto "vetusto" de todos los edificio e instalaciones, los pisos descuidados con aspecto "negro y feo", las "deficiencias de precaución y seguridad" y las carencias en cuanto a normas de higiene (Bialet Massé 1904: 106); una percepción totalmente opuesta a la presentada una década antes en la exposición de Chicago.

Tras comparar la fotografía que aquí presentamos -la única de Lastenia en la publicación- con la monumentalidad apreciable en otras imágenes de fábricas de azúcar abordadas en el informe, sostenemos que, lejos de suponer una percepción positiva del ingenio, esta representación ubica a Lastenia en un lugar acorde a la impresión que el autor expone en el texto.

La tercera fuente analizada (Figura 6) es una tarjeta postal fechada -a mano- en 1908. Sin embargo, no tenemos un dato certero acerca de la fecha exacta en que fue tomada la fotografía. En este sentido, a primera vista, sólo sabemos que la misma fue tomada con anterioridad al 30 de abril de 1908.

Más allá de que no exista una fecha exacta para datar a la Figura 6, si consideramos la presencia de los elementos compositivos de la imagen -gran cantidad de cañas, obreros trabajando, un número importante de vehículos destinados al traslado de caña- podemos sostener con seguridad que la misma fue tomada durante la época de zafra, es decir entre fines de mayo y principios de septiembre; por lo tanto, la fecha 30/04/08 -previa al inicio de la zafra de este año- nos indica que la fotografía en realidad no se corresponde con el año 1908. Por otra parte, si comparamos a las edificaciones apreciables con las registradas por Bialet Massé en 1904, notamos ampliaciones en los edificios $\mathrm{E}$ y $\mathrm{H}$-un aspecto que abordaremos más adelante-, lo que indica que la imagen es posterior a esta última.

En función de lo mencionado, si bien hasta el momento no hemos podido definir una fecha exacta para la fotografía, podemos asumir que durante el año 1907 el canchón habría tenido las características apreciables en la Figura 6, por lo que en adelante utilizaremos esta fecha como referencia para la fuente.

A nivel Arquitectónico, el análisis pre-iconográfico de la Figura 6 nos permitió definir cambios en las características del sector.

G - Fachada norte del edificio, apreciable también en la Figura 5, posee un vano circular en su parte superior y cubierta a dos aguas. 

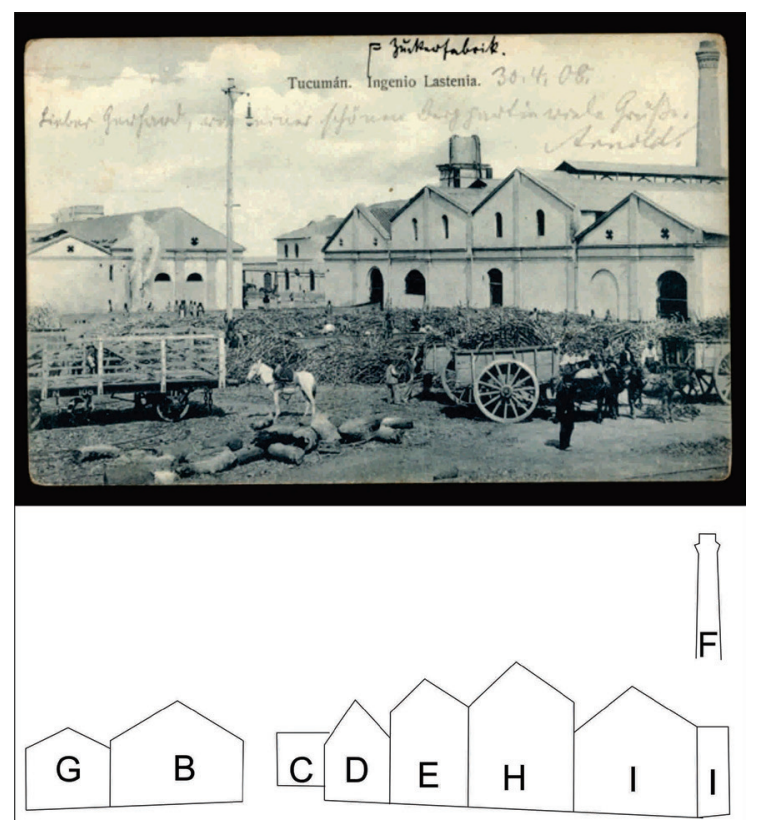

Figura 6. Arriba: Tarjeta postal datada en 1907. Presenta imagen del canchón del Ingenio Lastenia. Abajo: Contorno de la fachada de las edificaciones presentes en la imagen.

Figure 6. Postcard dated 1907. It presents an image of the Lastenia Sugar Mill yard. Bottom: Facade outline of the buildings present in the image.

B - Fachada norte, presenta las mismas características ya descriptas para 1904, aunque en esta ocasión, dada la distancia y la calidad de la imagen, permite apreciar las molduras y las pilastras a las que se hizo referencia en la descripción de referencia para 1892.

C - Fachada este del edificio de dos niveles ya descripto para 1904. Se observan cinco vanos definidos por arcos.

D - fachada descripta en referencia a las dos imágenes anteriores, conserva las mismas características destacadas en el grabado de 1892. Al igual que en 1904, se aprecia sobre su parte posterior un tanque de agua sobre una estructura cuadrangular.

E - Edificio adosado a " $D$ " presenta cambios con respecto a las características destacadas en las imágenes anteriores. La altura de la estructura es ahora superior a la de " $D$ ", posee una cubierta a dos aguas de chapa con un tragaluz. Los vanos apreciables sobre la fachada ya no son circulares, y cada uno de ellos está definido por arcos. En lo que respecta a la planta inferior, el acceso conserva las características observadas en las imágenes anteriores, mientras que la abertura cuadrangular registrada en 1904 sobre la derecha de la fachada no está presente en esta fotografía. Al igual que los grabados de 1892, se distinguen molduras horizontales que atraviesan la fachada. Posee una pilastra central que se extiende desde el piso hasta la altura de la cumbrera del techo.
F -Chimenea sur, observable hacia la derecha en la fotografía, presente en 1892.

$\mathrm{H}$ - Edificio adosado a "E", su fachada posee las mismas características que este último y al igual que él, presenta modificaciones en relación a 1904.

I-Edificio adosado a " $\mathrm{H}$ ", la fachada este del edificio parece conservar las características destacadas para la imagen de 1904, aunque permite apreciar tres rasgos no perceptibles en aquella, la pilastra central de la estructura, un arco hacia la izquierda de la misma y molduras horizontales.

En lo referente a los elementos no arquitectónicos registrados en esta fase del análisis, destacamos la presencia de al menos 27 personas, muchas de las cuales están reunidas frente al edificio "B", exactamente en el mismo lugar que las representadas en el grabado de 1892. En esta imagen es clara la vinculación de estas personas con una estructura longitudinal que atraviesa el vano de acceso de " $D$ " ingresando al edificio. Las características de esta estructura son coincidentes con las de una conductora de caña, una especie de cinta transportadora en la que se carga la caña para ser trasladada automáticamente hacia el trapiche donde es molida a fin de extraer su jugo.

En la fotografía es posible identificar, además, una gran cantidad de caña, al menos cinco animales -entre caballos y mulas-, tres carros cargados de caña y un vagón pequeño, algunos leños y un poste con una luz en el centro del espacio abierto.

El análisis iconográfico de la imagen demuestra claramente que se trata del canchón del ingenio de azúcar. La representación posee la particularidad de otorgar dinámica al contexto, puesto que la acción del trabajo es perfectamente apreciable. Se distinguen individuos descargando caña de los carros y otros montados a caballo, mientras, las personas ubicadas en el sector de la conductora de caña frente al edificio " $\mathrm{B}$ " aparentemente están cargando la maquinaria.

Por otro lado, la fuente aporta datos referentes a la tecnología utilizada en la época, como la energía eléctrica para la iluminación del área de trabajo, la mencionada conductora y la utilización de diversos medios de transporte para el traslado de la caña. Por último, los troncos sugieren la utilización de leña como combustible para las calderas de la fábrica.

Desde el punto de vista iconológico, para indagar en la significación de la imagen debemos considerar que la misma se trata de una tarjeta postal. Para aproximarnos a su contenido debemos considerar la relevancia de este tipo de objetos dentro del contexto histórico estudiado. Los primeros años del siglo XX fueron la edad de oro de las tarjetas postales (López Hurtado 2013), su fabricación 
masiva, su bajo costo y la aparición de publicaciones especializadas, prosperó junto con su popularización y con el coleccionismo postal en el mundo entero. En simultáneo con este auge, las tarjetas postales -un objeto masivo, coleccionable y vendible- comenzaron a ser empleadas también como elemento publicitario (López Hurtado 2013), pues su circulación -de escala mundial- otorgaba a las fábricas y a la región representada una gran visibilidad en diversos países. En función de lo mencionado, consideramos que uno de los principales aspectos de la imagen, en cuanto a su significación radica, precisamente, en su intencionalidad propagandística.

La cuarta, y última fuente analizada (Figura 7), se trata de una fotografía publicada en el libro El Norte Argentino (Padilla 1922).

El análisis pre-iconográfico de la Figura 7, a primera vista, denota importantes modificaciones a nivel edilicio.

$\mathrm{G}$ - apenas podemos distinguir la parte superior de su fachada norte, delante de esta se observa un nuevo edificio "L", que se adosado hacia el norte de las estructuras "G" $y$ " $B$ ".

B - También parcialmente cubierto por " $L$ ", solo podemos observar su cubierta a dos aguas, la parte superior de la pilastra central de la fachada norte del edificio, así como también las molduras y los dos vanos superiores visibles desde 1892.
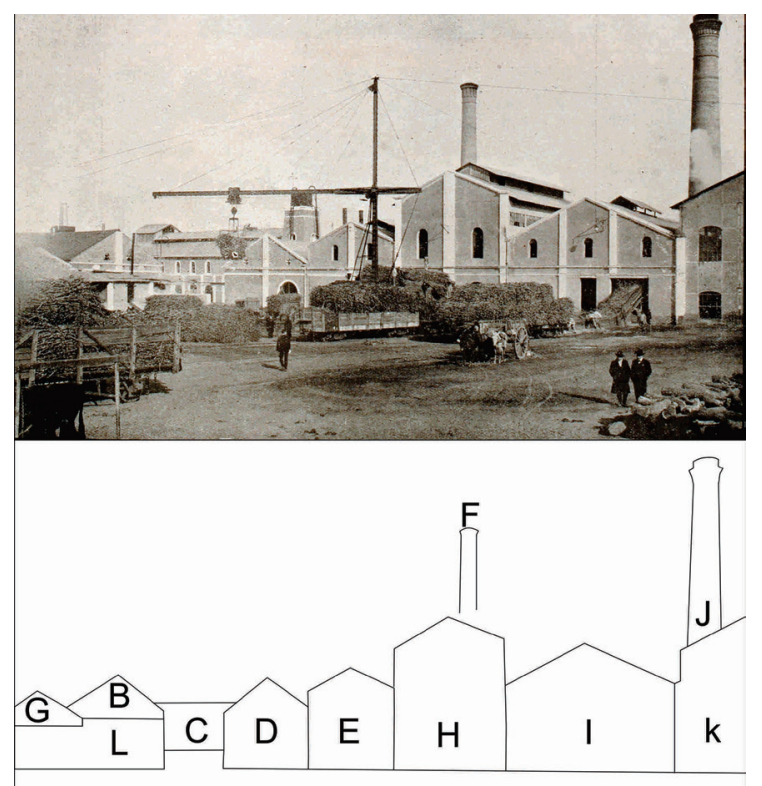

Figura 7. Arriba: El Canchón del Ingenio Lastenia en una fotografía publicada en El Norte Argentino (Padilla 1922). Abajo: Contorno de la fachada de las edificaciones presentes en la imagen.

Figure 7. Above: The Lastenia Sugar Mill yard in a photograph published in El Norte Argentino (Padilla 1922). Bottom: Facade outline of the buildings present in the image.
L - Edificación con cubierta a un agua, adosada a "G" y "B" y significativamente más baja que estas, aparentemente es de tipo galería.

C - La fachada este del edificio conserva las características descriptas en las imágenes de 1903 y 1907 -dos niveles y vanos definidos por arcos de medio punto en ambos niveles-. Sin embargo, la cubierta del edificio revela diferencias sustanciales con las imágenes anteriores, en esta ocasión se observa un tragaluz dispuesto a lo largo de la parte superior de la cubierta del edificio que, sobre el extremo sur, posee una pequeña estructura con techo a dos aguas que constituye un tercer nivel, inexistente en las imágenes anteriores.

D - Los rasgos apreciables en la fachada de la edificación sugieren que el edificio conserva las mismas características de 1907.

E - La edificación está parcialmente cubierta por pilas de atados de caña, por lo que solo es posible apreciar la parte superior de su fachada este, sector del edificio que conserva las características expuestas para la imagen de 1907.

F - Chimenea sur de la fábrica, su capitel presenta diferencias con el observable en 1907.

$\mathrm{H}$ - Edificio adosado a "E", exceptuando a las chimeneas, es la edificación de mayor altura en la fotografía, la parte inferior de su fachada este no es apreciable debido a los atados de caña que ocupan el centro del canchón. En cuanto a los niveles superiores del edificio, la fachada, al ser comparada con la imagen de 1907, denota una significativa ampliación hacia arriba, y una pilastra que se extiende hasta la altura de la cumbrera del techo. Los vanos superiores, definidos por arcos de medio punto, ocupan el mismo lugar que en las imágenes de años anteriores, aunque en este caso sus dimensiones son muy superiores. Posee cubierta a dos aguas con un tragaluz también de grandes dimensiones. Por último, sobre la parte superior de su fachada norte, a una altura superior a la cubierta de "I", se observan grandes ventanales vidriados.

I - Edificio adosado a " $\mathrm{H}$ ", la parte inferior de su fachada este está parcialmente cubierta por atados de caña, en la imagen pudimos identificar dos vanos cuadrangulares de acceso al edificio, uno de los cuales -el derecho- está atravesado por una conductora de caña. Se observan además dos pilastras. En su parte superior se pueden identificar tres vanos definidos por arcos de medio punto. En cuanto a la cubierta del edificio, presenta un techo a dos aguas con un tragaluz en su parte superior. Al comparar esta imagen con la de 1907, la ampliación hacia arriba y hacia los lados es muy notable.

J - Chimenea norte, ubicada detrás de "I".

K - Edificación adosada a "I", ubicada hacia la derecha 
de la fotografía, solo es parcialmente apreciable. Posee dos niveles con ventanales vidriados definidos por arcos de tipo escarzano (Ching 2015). Finalmente, debemos considerar los 15 cuadrantes -incluyendo los vanos de los ventanales- distinguibles sobre la fachada este del edificio y que sugieren la utilización de un entramado de hierro para su construcción (Ger y Lobez 1898).

Elementos no arquitectónicos, en la figura aparecen al menos 14 personas, la mayor parte de ellas trabajando en los atados de caña y en una conductora vinculada al edificio "I", en el que también se aprecia una luminaria colgada a gran altura. Un elemento particular, son los dos individuos ubicados sobre la esquina inferior derecha de la imagen, posando para la foto y con atuendos de época que los diferencian claramente de los obreros. El centro del canchón está dominado por la presencia de una grúa -ausente en las imágenes de años anteriorespara carga y descarga de atados de caña perfectamente organizados. También se destacan tres carros y un vagón, ambos vehículos utilizados para el traslado de caña desde los cañaverales o cargaderos hacia el ingenio.

Al igual que la imagen de 1907, la escena observada en la fotografía de 1922 otorga dinámica al espacio estudiado. Los numerosos atados de caña y las maquinarias -grúa y conductora- en funcionamiento, sugieren que la imagen fue tomada durante la época de zafra -entre fines de mayo y principios de septiembre-, pues la fábrica está claramente en proceso de molienda, actividad que no se llevaba a cabo en otra época del año.

Desde la significación, la imagen denota un claro interés por demostrar la magnitud de la fábrica y su capacidad productiva. Los textos que la acompañan en la publicación El Norte Argentino tienen una intencionalidad claramente publicitaria. Tal como deja entrever el propio autor, en la sección denominada "Nuestro propósito" (Padilla 1922: 7) la obra busca, "Reflejar lo que es" el norte de la República Argentina para que el lector conozca sus riquezas, lo que se explota y lo que hay por explotar; con esto Padilla pretende contribuir al impulso de la inmigración, las inversiones nacionales y extranjeras, así como también al turismo en la región. Las numerosas imágenes de contextos industriales -además de Lasteniaque presenta el volumen, reflejan la intencionalidad del autor, de demostrar el desarrollo de la región y romper con la idea de "retardo en el progreso moral y material" (Padilla 1922: 7) que existía acerca de muchas regiones del país, entre ellas el NOA.

\section{Discusión y Conclusiones}

\section{Ubicación, trabajo y tecnologías}

Los análisis realizados sobre fuentes iconográficas posibilitaron llevar adelante un estudio exhaustivo del canchón del ingenio como condición previa a una intervención directa en el campo. En primer lugar, se logró ubicar con precisión el sector estudiado y definir, además del canchón, un importante número de estructuras apreciables en la imagen de 1928, que hoy ya no están en pie y cuya identificación ha sido posible a partir de la metodología aplicada. Si bien no todas estas estructuras han sido abordadas sistemáticamente en este artículo por exceder a los objetivos del mismo; todas han sido debidamente registradas para trabajos futuros.

En segundo lugar, el análisis de las fuentes correspondientes a los años 1892, 1904, 1907 y 1922 (Figuras 3, 5, 6 y 7), permitió acercarnos al paisaje fabril de Lastenia en diversas épocas, obteniendo diferentes perspectivas del área estudiada y de los procesos de trabajo desarrollados en ella, así como también de las tecnologías utilizadas hacia fines del siglo XIX y principios del XX. Asimismo, el análisis iconológico de cada una de las representaciones nos lleva a concordar con puntos de vista procedentes de la Sociología y la Historia del Arte que sostienen que las imágenes poseen información acerca de la intencionalidad y posición social de quien realizó o encargó una obra, así como de la época o del momento social e histórico en que la misma fue realizada (Barboza Martínez 2006). Tal como exponemos a continuación, las representaciones analizadas contienen información acerca de los valores, -ligados a la revolución industrial y a la idea de progreso- de un determinado sector social en una época específica; así como también acerca de las diferentes perspectivas que existían entorno del espacio analizado durante el lapso abordado.

De las cuatro fuentes analizadas, tres (Figuras 3, 6 y 7) son representaciones dinámicas que permiten percibir movimientos y acciones vinculadas al trabajo y a la producción; los obreros trabajando, el humo expulsado de la chimenea principal, los vehículos cargados de caña, maquinarias como las conductoras y la grúa funcionando, son aspectos claros en este sentido. Dos de estas tres figuras (Figuras 3 y 7) forman parte de obras que buscan publicitar la industria y contienen discursos grandilocuentes sobre la fábrica (República Argentina 1892, Padilla 1922). Por su parte, la Figura 6, una tarjeta postal, fue impresa durante la primera década del siglo XX -la "era dorada de las tarjetas postales" (Harris 2020, López Hurtado 2013)- Ilevando la imagen y el nombre de la fábrica a distintos puntos del mundo -Por ejemplo, la tarjeta que aquí analizamos tenía por destino Berlín-, en un momento en que los fines publicitarios comenzaban a incorporarse al universo de las postales (López Hurtado 2013).

En función de lo mencionado, consideramos que las escenas retratadas -confeccionadas en los tres casos con finalidades promocionales- buscaron potenciar la idea de producción y éxito de la fábrica; estando ligadas estas percepciones a las ideas industrialización y progreso como sinónimo de civilización y mejora de la condición humana; concepciones del mundo originadas en Europa occidental, difundidas y adoptadas durante los siglo XIX 
y XX en gran parte del mundo, fundamentalmente entre las élites (Burns 1990; Gudynas 2011).

Por su parte, la representación de 1904 (Figura 5), muestra una imagen estática del área. En ella no hay trabajadores, vehículos o caña en proceso, solo se puede apreciar una imagen del canchón vació y de los edificios que componen la fábrica. La foto tomada por Bialet Massé en Lastenia no tiene un perfil publicitario, ni representa a una industria activa y pujante, más bien vemos en ella todo lo contrario. De hecho, como ya ha sido expuesto, en el texto asociado a la misma, el autor transmite una percepción muy negativa de la unidad de producción, lo que, a nuestro criterio, se ve reflejado en la imagen.

También hemos logrado acceder, a partir de los análisis realizados, a elementos que nos permitieron indagar en las formas de trabajo y las tecnologías vigentes durante el lapso estudiado, las imágenes más relevantes en este sentido son las de 1907 y 1922 (Figuras 6 y 7). El primer punto que destacamos en lo referente a estas fuentes, se vincula al sistema de descarga y carga de la caña. La grúa presente en 1922 (Figura 7), representa un importante avance en relación a los mecanismos perceptibles en las imágenes anteriores; en 1907 (Figura 6) no existe en el canchón maquinaria de este tipo y se ve claramente a dos individuos junto a los carros realizando manualmente el trabajo de descarga de caña, actividad que hacia 1922 era realizada por una máquina específica para dicho fin. Estas situaciones también explican la distribución de la caña en ambas imágenes, mientras que en la Figura 6 se puede apreciar a la caña distribuida por el canchón sin un orden claro; en 1922 (Figura 7), las cantidades de caña son muy superior y se observan pilas de atados perfectamente acomodados entorno de la grúa que al momento de ser tomada la fotografía estaba en plena actividad.

Otra innovación tecnológica notable en la documentación analizada es la presencia de una gran conductora de caña en 1922, ausente en las fuentes correspondientes a años anteriores, en las que, si bien hay evidencias del uso de maquinarias de este tipo (Figura 6), la misma presenta características distintas; esta variación en la conductora es coincidente con las diferencias en cuanto a cantidad de caña observable, con los cambios mencionados en el párrafo anterior y con importantes modificaciones apreciables en el plano arquitectónico.

Un último aspecto inferido tras analizar la posición de las conductoras en las imágenes, en 1907 asociada al edificio "D" y 1922 al "I", es el cambio en la ubicación de los trapiches, pues estas maquinarias normalmente estaban alineadas al molino, del cual recibían su movimiento de manera directa (Lavenir 1901). Por lo tanto, un cambio en la posición de las primeras implicaría un cambio del mismo tipo sobre los segundos.

Los carros tirados por mulas y el ferrocarril, vehículos utilizados para el transporte de la caña, son otro de los aspectos apreciables en las fuentes. Los primeros son evidentes en las fuentes correspondientes a 1907 y 1922, mientras que para el ferrocarril hay evidencias de su uso -vagones y/o vías- desde 1904 en adelante. Con respecto a las energías utilizadas en la fábrica, las grandes chimeneas dan cuenta de la utilización del vapor al menos desde 1892, información que está respaldada por numerosas fuentes escritas tanto primarias como secundarias (Rodríguez Marquina 1890, República Argentina 1892; Schleh 1945, Villar 2016, Campi 2017). Por otra parte, las lámparas eléctricas denotan el uso de este tipo de energía en la iluminación del sector estudiado, al menos desde 1907.

Finalmente, las fuentes también dan indicios acerca de los combustibles utilizados, la presencia de una gran cantidad de leña (Figuras 5, 6 y 7), sugiere la utilización de este recurso en las calderas del ingenio y da cuenta de la relevancia del mismo para el desarrollo y funcionamiento de la industria azucarera.

En función de los aspectos mencionados, sostenemos que entre 1892 y 1922, la fábrica en su conjunto experimentó importantes cambios a nivel de sistemas tecnológicos empleados, de capacidad de procesamiento y de capacidad productiva.

\section{Arquitectura y Cronología}

Las fuentes iconográficas han sido muy utilizadas por diversos investigadores para complementar estudios desde la arqueología de la arquitectura (Blanco Rotea 2010; Caballero Zoreda 2010) y son un respaldo fundamental para llevar adelante estudios relativos a las dinámicas constructivas de la fábrica, a los diversos materiales constructivos y técnicas arquitectónicas empleadas de manera simultánea o en diferentes momentos históricos (Azcárate 2010; Blanco Rotea 2010; Caballero Zoreda 2010).

A partir de los análisis de las edificaciones representadas en las Figuras 3, 4, 6 y 7, se obtuvieron descripciones detalladas que otorgan un panorama general sobre las características y las modificaciones experimentadas por el entorno construido, entre 1892 y 1922. Los datos obtenidos posibilitaron la elaboración de una secuencia cronológica relativa a partir de la cual inferimos los momentos en que las edificaciones vinculadas al canchón de la fábrica estuvieron sujetas a modificaciones estructurales (Figura 9).

Si bien, es muy probable que las intervenciones en las edificaciones hayan sido constantes, las fuentes iconográficas dan testimonios concretos sobre las intervenciones más importantes efectuadas sobre las estructuras arquitectónicas analizadas. El Gráfico 1 da cuenta de los momentos en los que estas intervenciones se llevaron a cabo en el lapso estudiado a partir de fuentes 


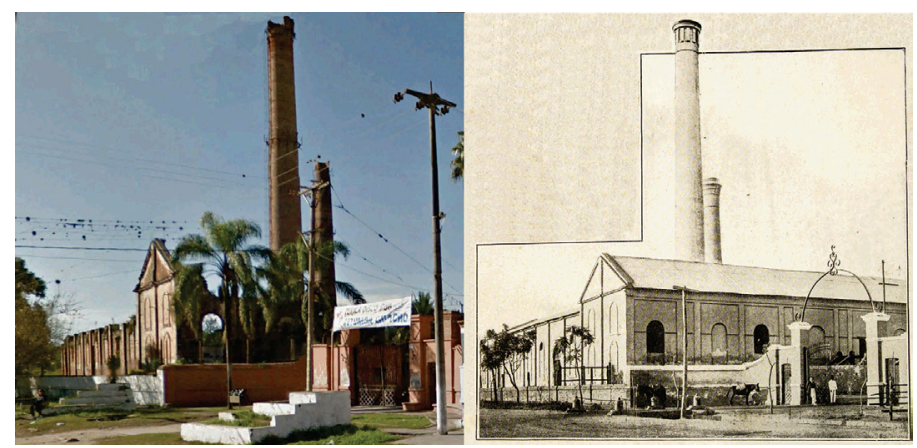

Figura 8. Fotografías del Sitio Ingenio Lastenia (SIL) tomadas desde el exterior de la puerta principal de la planta en sentido suroeste-noreste. Izquierda: 2016. Derecha: 1916. El coronamiento de la chimenea sur presenta las mismas características que en 1922.

Figure 8. Photographs of the Ingenio Lastenia Site (SIL) taken from outside the main door of the plant in a southwest-northeast direction. Left: 2016. Right: 1916. The crest of the south chimney has the same characteristics as in 1922. iconográficas 1892 - 1922.

El edificio " $A$ " presente en la Figura 3, desapareció antes de 1904, posiblemente para dar lugar a la construcción de "G" en el mismo lugar. Por su parte " $G$ ", en aparente construcción en la Figura 5, habría conservado sus características generales hasta 1922. Con respecto a "B", la estructura mantuvo sus características generales a lo largo de los 30 años que van de 1892 a 1922.

En " $C$ " registramos tres etapas constructivas y dos intervenciones importantes; la primera etapa fue previa a 1892, entre este año y 1904 se dio la primera intervención registrada -anexión de un segundo nivel- que se corresponde con una segunda etapa constructiva; la segunda modificación -tercera etapa constructiva- se dio entre 1907 y 1922, año para el cual registramos una importante remodelación de su cubierta y la construcción de un tercer nivel.

El edificio " $D$ ", mantuvo sus características generales desde 1892 hasta 1922. Para "E" registramos las mismas características durante 1892 y 1904, sin embargo, para 1907 ya presentaba modificaciones que le otorgaron las características que aún conservaría en 1922.

La estructura " $F$ ", chimenea sur de la fábrica, está presente en el grabado de 1892 y su corona presenta las mismas características que la observable en 1907. Sin embargo, en la imagen de 1922 las características de este sector de la chimenea son muy diferentes, lo que denota, dada la complejidad que significaba un cambio de este tipo (De las Rivas y López 1905), una modificación sustancial entre 1907 y 1922. Este análisis comparativo fue complementado con otra fotografía de la fábrica, publicada en 1916 (Figura 8), en el Álbum General de la Provincia de Tucumán, en el primer Centenario de la Independencia Argentina (República Argentina 1916). Este trabajo permitió definir que dicha modificación tuvo lugar entre 1907 y 1916, pues en la imagen del álbum la corona de la chimenea sur de la fábrica presenta las mismas características que en 1922.

El edificio " $H$ " No es apreciable en la imagen de 1892, no hemos logrado determinar si por ese año no existía o simplemente no fue incluido en el grabado. Lo cierto es que solo contamos con registro de él a partir de 1904, desde entonces la construcción estuvo sujeta a una ampliación muy significativa que quedó evidenciada en las imágenes analizadas. La primera intervención evidente tuvo lugar entre 1904 y 1907, mientras que la segunda se dio en algún momento posterior a 1907 y previo a 1922. Al igual que " $\mathrm{H}$ ", "I" tampoco ha sido registrado sino hasta 1904, a partir de nuestros análisis hemos registrado una ampliación significativa entre 1907 y 1922.

En relación a "J", la chimenea norte de del SIL, la estructura tampoco fue registrada hacia 1892. Sin embargo, a diferencia de lo sucedido con " $\mathrm{H}$ " e "I" en su caso sabemos que para ese año el SIL solo contaba con una chimenea (Ver Figura 4), la chimenea sur. Por lo tanto, sabemos que "J" fue construida entre 1892 y 1904, año en el que aparece registrada por primera vez en las imágenes estudiadas.

Otra de las estructuras registradas es " $\mathrm{K}$ ", la misma fue construida después de 1904, pues la imagen correspondiente a este año es una percepción general

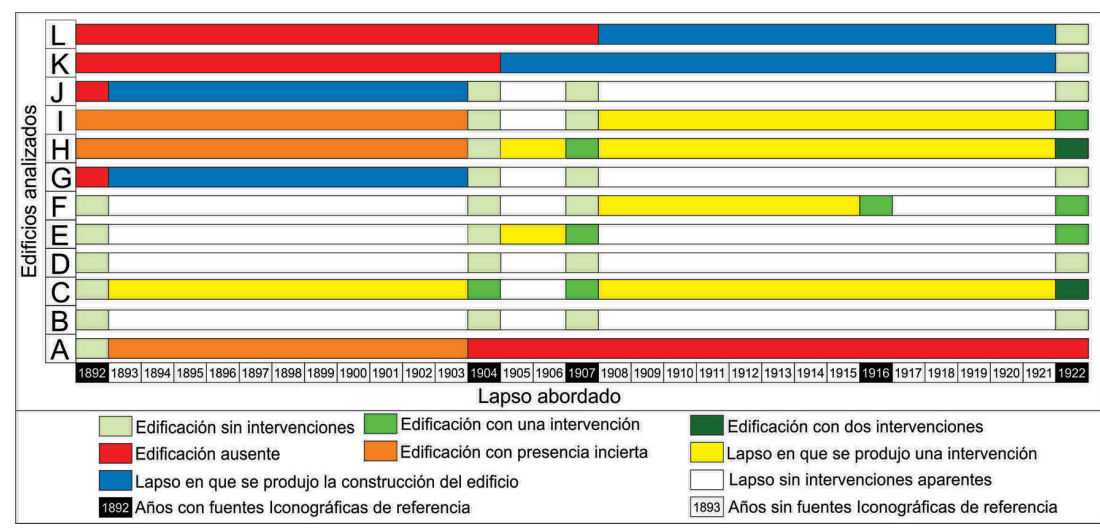
del canchón de la fábrica, en ella queda evidenciada la ausencia de construcciones en el sector que para

Figura 9. Secuencia cronológica de las etapas constructivas de las estructuras arquitectónicas analizadas.

Figure 9. Chronological sequence of the construction stages of the analyzed architectural structures. 
1922 observamos a "K". Por último, la estructura "L", apenas visible en la última fuente de 1922 y ausente en la de 1907, fue construida en el lapso que separa estos dos años.

\section{Consideraciones finales}

A lo largo de este artículo hemos logrado establecer un panorama general de las características del canchón del ingenio Lastenia, de las practicas realizadas en él, de los cambios en el entorno a nivel tecnológico e incluso de diversas percepciones de la fábrica coexistentes en el lapso abordado.

Los resultados del análisis de fuentes iconográficas constituyen un marco de referencia cronológico invaluable que, tras ser complementados con trabajos de campo, permitirán profundizar aún más avanzando en la comprensión de la dinámica constructiva de la fábrica, posibilitándonos fechar edificaciones, materiales utilizados, elementos constructivos y técnicas arquitectónicas empleadas. Asimismo, este avance posibilitará la conformación de una secuencia de referencia que podrá ser utilizada para interpretar edificaciones sobre gran parte del sitio.

Para finalizar queremos subrayar dos aspectos que, consideramos, han quedado plasmados en este trabajo y poseen una gran relevancia para el desarrollo de investigaciones dentro de un marco ArqueológicoIndustrial. En primer lugar, nos referimos al valor de las fuentes iconográficas para el estudio del pasado de contextos histórico-industriales, pues como ha quedado expuesto, el análisis de fuentes de este tipo ofrece amplios y diversos aportes. En segundo lugar, remarcamos la relevancia que posee para el estudio de documentos de este tipo, el vínculo con disciplinas especializadas en el estudio de imágenes como lo es la Historia del Arte, que aporta herramientas metodológicas e interpretativas que poseen un gran potencial para el desarrollo de investigaciones arqueológicas.

\section{Agradecimientos}

A la Sra. Beatriz Tula, propietaria del predio donde funcionó el Ingenio Lastenia, por posibilitar los trabajos en el sitio. A los Dres. Salomón Hocsman y Daniel Campi por su apoyo y sugerencias en todo momento. Al Laboratorio de Digitalización del Instituto Superior de Estudios Sociales y en especial a Carlos Darío Albornoz por el material fotográfico. Este trabajo se desarrolló en el marco de los Proyectos PIUNT H552/3 "La cuestión social en Tucumán, 1888-1923. Debates, controversias, políticas" y PUECONICET 093 "Patrimonio, Territorios e Identidades: trayectorias de larga duración en el Norte argentino desde tiempos prehispánicos hasta la actualidad", dirigidos por el Dr. Daniel Campi, y de la tesis doctoral "Producción, cotidianeidad y disciplinamiento social en un Ingenio Azucarero durante el siglo XIX. Una aproximación al Sitio Ingenio Lastenia (Dpto. Cruz Alta, Tucumán) desde la
Arqueología Industrial", del primero de los autores.

\section{Bibliografía}

Agustín Lacruz, M. C. (2010). El contenido de las imágenes y su análisis en entornos documentales. Polisemias visuales aproximaciones a la alfabetización visual en la sociedad intercultural. Universidad de Salamanca. España.

Azkárate, A. (2010). El análisis estratigráfico en la restauración del patrimonio construido. Consideraciones conceptuales e instrumentales. En Arqueología aplicada al estudio e interpretación de edificios históricos. Últimas tendencias metodológicas (pp. 51-63). Secretaría General y Técnica. Ministerio de Cultura. España.

Barboza Martínez, A. (2006). Sobre el método de la interpretación documental y el uso de las imágenes en la sociología: Karl Mannheim, Aby Warburg y Pierre Bourdieu. Sociedade e Estado,21(2), 391-414.

Bialet Massé, Juan (1904), Informe sobre el estado de la clase obrera (Tomo III). Imprenta y casa editora de Adolfo Grau. Buenos Aires.

Burns, B. (1990). La pobreza del Progreso. Siglo XXI, México.

Caballero Zoreda, L. (1995). Método para el análisis estratigráfico de construcciones históricas o Lectura de paramentos. AA.W., Leer el documento construido. Informes de la construcción 435, 37-45.

Caballero Zoreda, L. (2010). Experiencia metodológica en Arqueología de la Arquitectura de un grupo de investigación. En: Arqueología aplicada al estudio e interpretación de edificios históricos. Últimas tendencias metodológicas. (pp. 103-119). Secretaría General y Técnica. Ministerio de Cultura. España.

Campi, D. (2017). Unidades de producción y actores en los origenes de la actividad azucarera. Tucumán, 1830-1876. FACE - UNT. San Miguel de Tucumán.

Casado Galván, I. (2009). Fuentes escritas, orales e iconográficas de la arqueología industrial. Contribuciones a las Ciencias Sociales. Disponible en: https://ideas.repec.org/a/erv/coccss/ y2009i2009-126.html (Último acceso: 19/05/2020).

Ching, F. (2015). Diccionario Visual de Arquitectura. Gustavo Gili, SL. México.

De las Rivas y López, M. (1905). Chimeneas de Fábrica. Teoría - Calculo de sus dimensiones - Estabilidad - Construcción. Imprenta del memorial de Ingenieros del Ejército. Madrid.

Domeneghini, G. (2019). El eterno murmullo de los textos... Aplicación de métodos de análisis visuales interdisciplinarios en objetos arqueológicos de colección de la provincia de San Juan. Libro de Resúmenes del XX Congreso Nacional de Arqueología Argentina, 83-86.

Ger y Lobez, F. (1898). Tratado de Construcción Civil. 
Establecimiento tipográfico La minerva extremeña. Badajoz, España.

González Reyero, S. (2001). Los usos de la fotografía en favor de la arqueología como ciencia moderna. Francia 1850-1914. Cuadernos de Prehistoria y Arqueología de la Universidad Autónoma de Madrid (CuPAUAM) 27, 163-182.

Gudynas, E. y Acosta, A. (2011). El buen vivir o la disolución de la idea de progreso. En Mariano Rojas (Ed.) La medición del progreso y el bienestar. Propuestas desde América Latina. (pp.103-110). Foro Consultivo Científico y Tecnológico de México.

Guía de Tucumán (1928) Ingenio Lastenia. [Fotografía] Guía de Tucumán, Biblioteca del Museo de la Casa Histórica de la Independencia. San Miguel de Tucumán.

Harris, J. (2020). Vintage Postcards from the African World: In the Dignity of Their Work and the Joy of Their Play. University Press of Mississippi.

Januarius, J. y Teughels, N. (2009). History Meets Archaeology: the Historical Use of Images. A Survey. Revue belge de philology etd'histoire, 87(3-4), 667-683.

Kligmann, D. y Falchi, M. (2018). La imagen de la lagartija en la iconografía prehispánica del Noroeste Argentino I: una propuesta tipológica. EstudiosAtacameños 60, (97-131).

Latour, B. (1986). Visualization and Cognition: Thinking with Eyes and Hands. Knowledge and Society, 6, 1-40.

Lavenir, Pablo (1901), El cultivo de la caña y la elaboración del Azúcar en las provincias de Tucumán, Salta y Jujuy. Imprenta de P. Gadola, Buenos Aires.

López Hurtado, M. (2013). La Tarjeta Postal como Documento. Estudio de usuarios y propuesta de un modelo analítico. Aplicación a la colección de postales del ateneo de Madrid. Tesis Doctoral. Facultad de Ciencias de la Documentación. Universidad Complutense de Madrid. Tesis Doctoral Inédita disponible en: https://eprints.ucm.es/23004/ (Último acceso: 19/05/2020).

McGuire, R. y Reckner, P. (2005). Building a Working Class Archaeology. The Colorado Coal Field War Project. En: Collin Cassella, E. y Symons J. (Eds.). Industrial Archaeology. Future Directions(pp. 217-241) Springer, New York.

Moreno Pulido, E. (2007). Iconografía e Iconología desde el renacimiento hasta nuestros días. Su aplicación en la Arqueología. Revista Atlántica-Mediterranea de Prehistoria y Arqueología Social (RAMPAS), 9, 179-214.

Nassif, S. (2015).Las luchas obreras tucumanas durante la autodenominada Revolución Argentina. Tesis Doctoral. Facultad de Filosofía y Letras, Universidad de Buenos Aires, Buenos Aires. Disponible en: http://repositorio.filo.uba.ar/ jspui/bitstream/filodigital/3003/1/uba_ffyl_t_2015_899550. pdf (Último acceso: 19/05/2020).
Orser, C. (2017). Historical Archaeology. Routledge. New York.

Padilla, E. (1922). El Norte Argentino. Establecimiento Gráfico Ferrari Hnos. Buenos Aires.

Palmer, M. y Neaverson, P. (1998). Industrial Archaeology. Principles and Practice. Routledge. Londres-Nueva York.

Panofsky, E. (2001). Estudios sobre iconología. Alianza, España.

Prince, G. (1988). Photography for Discovery and scale by superimposing old photogrphs on the present-day scene. Antiquity 62, 112-116.

República Argentina (1892), Estadística Gráfica. Progreso de la República Argentina en la Exposición de Chicago, Empresa de la Patria llustrada, Año 1892. Archivo digital del Instituto Superior de Estudios Sociales (ISES).

República Argentina (1916). Álbum General de la Provincia de Tucumán, en el primer Centenario de la Independencia Argentina. Establecimiento Gráfico de M. Rodríguez Giles, Buenos Aires.

República Argentina (1966). Ley No 16.926". Boletín oficial No 21010 del 24 de agosto de 1966. En linea: http://servicios. infoleg.gob.ar/infoleglnternet/anexos/45000-49999/46625/ norma.htm (Último Acceso: 14/4/2020).

Rodríguez Marquina, Paulino (1890). Memoria descriptiva de Tucumán. La industria azucarera. Su presente, pasado y porvenir. Inédito. Archivo Histórico de la Provincia de Tucumán (AHT).

Ruiz Zapatero, G. (2014). Fotografías y arqueología: ventanas al pasado con cristales traslúcidos. En José Lovato (Ed.). Cuarenta años de fotografía arqueológica española (1976-2014) (pp.5371), Museo Arqueológico Regional. Madrid.

Schleh, E. (1945). Noticias históricas sobre el azúcar en la Argentina. Centro Azucarero Argentino. Buenos Aires.

Shanks, M. y Svabo, C. (2013). Archaeology and photography. A pragmatology. En González Ruibal, A. (Ed.) Reclaiming Archaeology. Be-yond the tropes of Modernity (pp. 89-102). Routledge, Londres-Nueva York.

Sobrino Simal, J. (1999). El paisaje, las máquinas y los hombres: la pintura como fuente de documentación social para la arqueología industrial. Antigrama, 14, 65-78.

Symonds, J. (2005). Experiencing Industry Beyond Machines and The History of Technology. En: Collin Cassella, E. y Symons J. (Eds.). Industrial Archaeology. Future Directions (pp. 33-57) Springer, New York.

Villar, Fernando (2016). Procesos de producción de derivados de la caña de azúcar en el Sitio Ingenio Lastenia (Dpto. Cruz Alta, Tucumán) entre 1835 y 1876. Una aproximación desde la Arqueología Industrial. Tesina de grado de la Carrera de Arqueología, Inédito. Facultad de Ciencias Naturales e Instituto Miguel Lillo, Universidad Nacional de Tucumán. 